As the astigmatism is still undercorrected, $\mathrm{C}_{3}$ is negative, and so $\cos 2 \gamma$ in (c) must be negative, i.e., $\cos 2 \gamma=\cos 122^{\circ} 18^{\prime}$ or $\gamma=61^{\circ} 9^{\prime}$ but $90^{\circ}-61^{\circ}=29^{\circ}$ and we must turn the cylinder $5^{\circ}$ clockwise, or practically about $\frac{1}{6}$ of the error suggested by the obliquity of the movement of the light. It will be found in this way that when the error in the position of the axis of the cylinder is $5^{\circ}$, if the error in the correction of the astigmatism be $1 \mathrm{D}$, whether in excess or defect, the obliquity of the movement of the light will magnify the real fault in position about four times, but if the error in the astigmatic correction be $0.5 \mathrm{D}$, the magnification of the fault in position will be about six times.

\title{
ANNOTATIONS
}

\section{Ship Lighting}

The Illuminating Engineering Society are gradually getting a collection of valuable papers on all lighting problems written by practical experts in their own line. One of the latest contributions appears in their Journal for May of this year and deals with the question of ship lighting in relation to safety, comfort and efficiency. The writer was Mr. W. J. Jones and in the subsequent discussion representatives of the Navy and mercantile marine took part. The problem of safe and efficient lighting of ships is a very special one with difficulties of its own. There seems to be very little literature on the subject. The Board of Trade regulations leave considerable latitude, and there seems to be but little effort at any system of standardization of illumination or fittings. The paper dealt mainly with technical details such as the nature of the lamps and fittings and the arrangements for indicating the failure of important lamps like sidelights, but several matters such as the efficient lighting of charts, etc., also received attention. It was suggested that as charts were made and examined by daylight some system of artificial daylight coming from below might bc better than the usual system. Captain Nicholson pointed out that the navigating officer in bad weather or coastal navigation avoided the chart room at night as far as possible, owing to the bright light preventing him from seeing anything for some time after coming out. He had found that by closing one eye, and keeping it closed while in the chart room, he was not affected in this way and could see quite well on coming out. Another interesting point noted by Commander Waller was that the Navy used twice as much light in the starboard light as in the port one on account of the greater absorption that took place in the green glass. 